\title{
LUT
}

University

\section{Magneto-Thermal Analysis of an Axial-Flux Permanent-Magnet-Assisted Eddy-Current Brake at High-Temperature Working Conditions}

Gülec Mehmet, Aydin Metin, Nerg Janne, Lindh Pia, Pyrhönen Juha

This is a Author's accepted manuscript (AAM) version of a publication

published by IEEE

in IEEE Transactions on Industrial Electronics

DOI: $\quad 10.1109 /$ TIE.2020.2992020

Copyright of the original publication: (C) 2020 IEEE

Please cite the publication as follows:

M. Gulec, M. Aydin, J. Nerg, P. Lindh and J. Pyrhonen, "Magneto-Thermal Analysis of an AxialFlux Permanent-Magnet-Assisted Eddy-Current Brake at High-Temperature Working Conditions," in IEEE Transactions on Industrial Electronics, doi: 10.1109/TIE.2020.2992020.

(C) 2020 IEEE. Personal use of this material is permitted. Permission from IEEE must be obtained for all other uses, in any current or future media, including reprinting/republishing this material for advertising or promotional purposes, creating new collective works, for resale or redistribution to servers or lists, or reuse of any copyrighted component of this work in other works.

This is a parallel published version of an original publication. This version can differ from the original published article. 


\section{IEEE $\mid \begin{aligned} & \text { Transactions on } \\ & \text { Industrial Electronics }\end{aligned}$}

Magneto-Thermal Analysis of an Axial-Flux PermanentMagnet-Assisted Eddy-Current Brake at High-Temperature Working Conditions

\begin{tabular}{|c|c|}
\hline Journal: & Transactions on Industrial Electronics \\
\hline Manuscript ID & 20-TIE-0203.R1 \\
\hline Manuscript Type: & Regular paper \\
\hline Manuscript Subject: & Actuators and Motors \\
\hline Keywords: & $\begin{array}{l}\text { Eddy currents, Electromagnetic analysis, Rotating machine nonlinear } \\
\text { analysis }\end{array}$ \\
\hline $\begin{array}{r}\text { Are any of authors IEEE } \\
\text { Member?: }\end{array}$ & Yes \\
\hline $\begin{array}{r}\text { Are any of authors IES } \\
\text { Member?: }\end{array}$ & Yes \\
\hline
\end{tabular}




\section{Magneto-Thermal Analysis of an Axial-Flux Permanent-Magnet-Assisted Eddy-Current Brake at High-Temperature Working Conditions}

\begin{abstract}
This paper proposes an analytic coupled magneto-thermal analysis of an axial-flux (AF) permanentmagnet-assisted (PMA) eddy-current brake (ECB) at hightemperature working conditions. In the topology investigated, permanent magnets (PMs) are placed into stator slot openings to increase the braking torque production capability. This modification enables to control the magnet flux by altering the DC excitation current. However, the utilization of PMs will make the construction vulnerable at high operating temperatures simply because the magnet properties and the brake capability are strongly dependent on temperature. Such problems require complex coupled multiphysics finite element analyses (FEA) to obtain the actual brake performance. The proposed approach offers a simple and effective solution that consists of magnetic and thermal models, which are coupled to each other in the time domain. The nonlinear electrical, magnetic and thermal properties are influenced by the temperature variation in time. An AF-PMA-ECB prototype is manufactured to validate the proposed coupled models and the experimental studies confirm that the proposed approach provides very practical results to determine the working conditions of the AF-PMA-ECB at high-temperature operations.
\end{abstract}

Index Terms-Axial flux machines, eddy current brakes, permanent magnet assisted eddy current brake, magnetothermal modeling.

\section{INTRODUCTION}

E LECTRICAL products will entirely shape our world in the future in such a way that efficient and innovative products will be dominant in the market. AF-ECBs have been used as a frictionless braking component over a century, and it seems that they will be used more intensively to fulfill different braking demands. ECBs will have a significant role especially in the traction market [1]-[4]. AF-PM and PMA-ECBs provide higher braking torque characteristic compared to traditional magnetless AF-ECB topologies. However, PM-ECBs need an external system to control the braking torque and PM flux [5][6]. An external system is also needed for almost all PMAECBs. In PMA-ECBs, the magnets can be placed in several places in the magnetic system, for example in the stator yoke or stator teeth or in the stator slot openings. Among these alternatives, the braking torque can be fully controlled only if the magnets are placed in the stator slot openings, where the PM flux can complete its path over the yoke when there is no excitation. PMs provide an advantage over other topologies but the magnets are elose to the brake disc, where a great amount of heat is released during braking resulting in a fast temperature rise. $\mathrm{NdFeB}$ PMs are very sensitive to high temperatures. When the PMs are exposed to high temperatures in ECBs, their magnetic properties will change causing some reduction in the braking torque. In addition, the temperature rise in the magnets should be checked to eliminate the danger of demagnetization and to determine the allowed braking time. Therefore, special attention should be given in modeling and analyses of the AFPMA-ECB coupling magnetic and thermal simulations. Such coupled problems can be solved by commercial multiphysics FEAs software, but existing software require far too long computation time even for practical design cases. A very limited number of papers focus on this issue in the literature. Ye et al. [6] introduced a novel electro-magnetic-thermal-fluid multi-physics coupling model for a radial-flux permanent magnet ECB by using commercial software. Jin et al. [7] presented an analytical thermal analysis of a hybrid excitation linear ECB. The authors built separate magnetic and thermal models and calculated the thermal contacts and airflow by a commercial computational fluid dynamics software. According to the understanding of the authors, no prior work on magnetothermal analysis for ECBs has been reported in literature.

In this work, a new analytical coupled magneto-thermal analy sis approach is proposed for AF-PMA-ECB to determine the working conditions at high temperature operating conditions as a fast and practical solution contrary to multiphysics FEAs software. Magnetic analy sis consists of 2dimensional (2D) reluctance network modeling, NewtonRaphson nonlinear solver and coupled Faraday's Law and Ampere's Law. In thermal analysis, 3D lumped parameter model is used to determine the temperature rise of each component. The proposed approach runs in the time domain and all nonlinear parameters are updated by temperature rise in each time step.

\section{INVESTIGATED AF-PMA-ECB}

The investigated AF-PMA-ECB has a single-rotor (brake disc)single-stator configuration and its structure is illustrated in Fig. 1-(a). PM magnetizations, excitation coils and flux paths are provided in Fig. 1-(b). The magnet driven flux completes its path over yoke without exaction current. PM flux can be altered by DC excitation during braking operation in this topology and 
it is possible to fully control the braking torque without external mechanisms as to [8]-[13]. The key parameters of the investigated AF-PMA-ECB are provided in Table I. The brake has $180 \mathrm{~mm} / 100 \mathrm{~mm}$ of outer-to-inner diameter ratio with an axial air gap, $g$, of $1 \mathrm{~mm}$. The brake disc has a thickness of 15 $\mathrm{mm}$. The N30UH type NdFeB magnets are used in the slot openings of the brake. Low carbon steel (ST37) is selected as brake disc and stator material [14] due to its low material cost. The maximum braking speed of the brake is selected as 2000 $\mathrm{min}^{-1}$ because of the limitations of the test system.

(a)

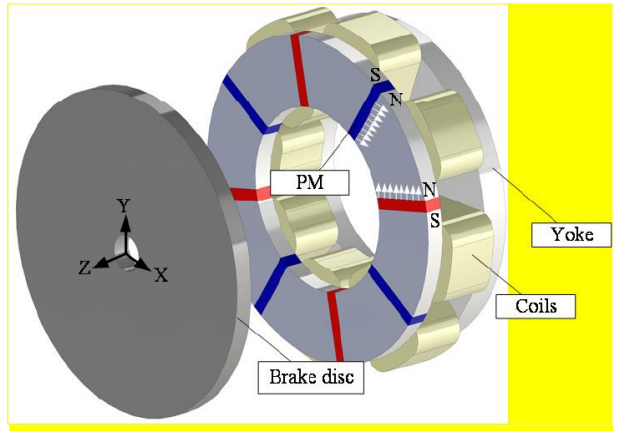

(b)

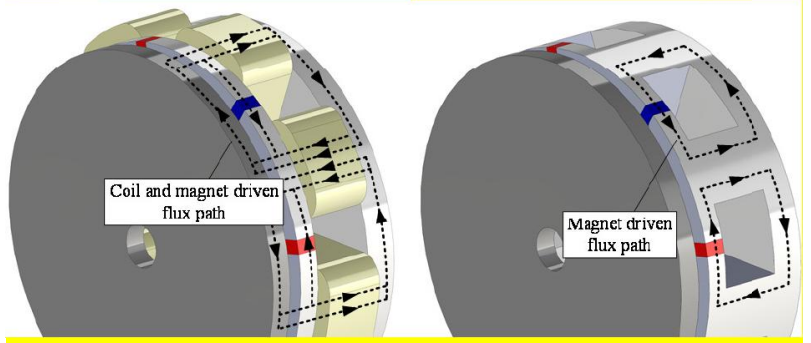

Fig. 1. (a) AF-PMA-ECB topology and (b) flux paths.

TABLE I

Key Parameters of The AF-PMA-ECB

\begin{tabular}{ll}
\hline \hline Stator teeth-to-pole ratio & 0.472 \\
Axial air gap, g, [mm] & 1 \\
Number of slots \& magnets & 8 \\
Turn number in the slot & $2 \times 172$ \\
Max. current density in the coil & $10 \mathrm{~A} / \mathrm{mm}^{2}$
\end{tabular}

Max. current density in the coil $\quad 10 \mathrm{~A} / \mathrm{mm}^{2}$

\begin{tabular}{ll} 
Stator and braking dise material & $\begin{array}{l}\text { Low carbon steel } \\
\text { (ST37) }\end{array}$ \\
Brake dise thickness [mm] & 15 \\
PM Type & N30UH \\
Magnet Size & $3.1 \times 10 \times 40 \mathrm{~mm}^{3}$ \\
PM $B_{\mathrm{r}}$ at room temp. & $1.1 \mathrm{~T}$ \\
PM $H_{\mathrm{c}}$ at room temp. & $860 \mathrm{~A} / \mathrm{m}$ \\
\hline \hline
\end{tabular}

\section{Proposed Coupled Magneto-Thermal Analysis APPROACH}

An analytic coupled magneto-thermal modeling is developed for the proposed $A F-P M A-E C B$ to determine the actual brake behavior. The proposed coupled magneto-thermal analysis approach aims to determine the braking torque variation, braking time and the temperature rise in time. The flowchart of the proposed approach is given in Fig. 2. The approach has two main stages: The first stage covers the magnetic analysis and the second stage deals with the thermal analysis. In the magnetic analysis, 2D reluctance network modeling and Newton-Raphson nonlinear solver are firstly applied to obtain the static air gap magnetic flux density and skin depth. Then, Faraday's Law and Ampere's Law are solved jointly to get the dynamic air gap magnetic flux density variation and the braking power. In the thermal analysis, a nonlinear 3D lumped parameter model is developed and temperature rise for all components are calculated.

The proposed approach starts with setting the initial parameters such as ambient temperature, operating speed, DC excitation current, $B H$-curve characteristic, PM hysteresis curve, resistivity, heat capacity, the braking time and critical temperature of the brake disc and magnets. In the first time step, magnetic analysis is performed by the initial values and the braking power is calculated. Next, computed braking power is used as an input in the thermal analy sis. Temperature rise for all nodes is calculated and the critical temperature of the brake disc and magnets is monitored at the end of the thermal analysis.

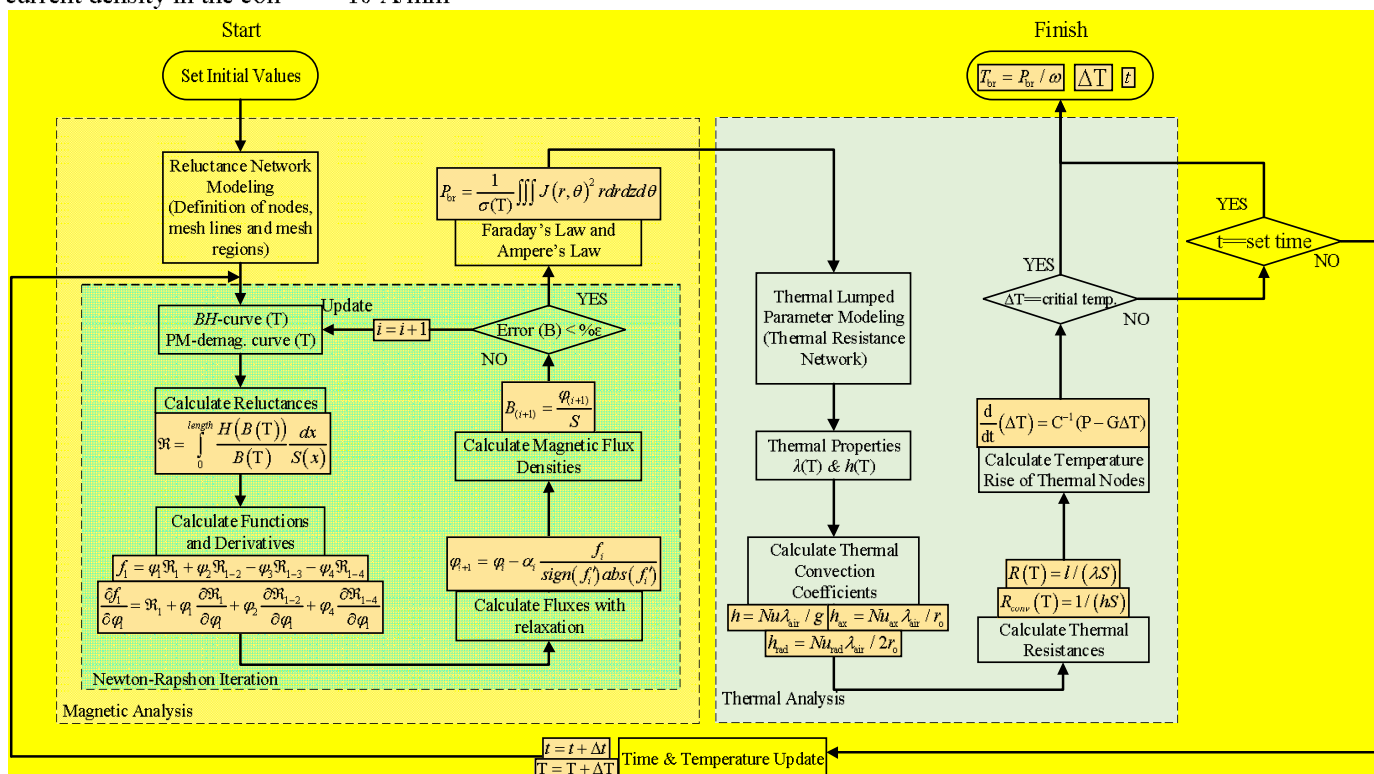

Fig. 2. Flowchart of the proposed coupled magneto-thermal modeling. 
Before updating the time and the temperature for the next time step, the braking time is compared with the set value and the process continues until the critical temperature of the brake disc or magnets is reached, or the braking time is completed. The material properties depended on temperature are updated in each time step. The $B H$-curve, PM hysteresis curve, resistivity and thermal properties are defined as a function of temperature in the proposed approach.

\section{A. Magnetic Analysis}

The investigated AF-PMA-ECB has 8 slots and as a result of symmetry, it can be modeled by concentrating on only one slot. The symmetric 2D model of the AF-PMA-ECB is illustrated in Fig. 3-(a). 2D model of the brake is obtained by a $\mathrm{z}$-axis cut plane, which is applied in the middle of the inner-outer diameter. In this case, the model depth is equal to the difference between the inner and the outer radius [15]-[16]. The black circles represent the mesh points and the red dashed lines represent the mesh lines. The air gap in the model is meshed by two horizontal layers to improve the accuracy of the results. The yoke and the slot regions are simply meshed to avoid heavy computation. The reluctance network model is given in Fig. 3(b). The $22 \times 22$ reluctance matrix and the $1 \times 22$ current linkage vector are generated to solve the matrix equation so as to find the mesh flux vector. The reluctances are defined by their $\mathrm{x}$ and y axes mesh information as described in Fig. 3-(b). To give an example, the PM reluctance as function of temperature is defined by

$\mathfrak{R}_{\mathrm{PM}}(\mathrm{T})=\frac{I_{\text {cint }}(100+b)}{B_{\text {rint }}(100+a)} \frac{x_{\mathrm{PM}}-x_{0}}{\left(y_{4}-y_{3}\right) d}$

where $B_{\text {rint }}$ is the remanent flux density at room temperature, $H_{\mathrm{c}}$ int is the intrinsic coercivity, $a$ is the temperature coefficient of the remanence ( $a=-0.09 \Delta T$ for UH magnet type), $b$ is the temperature coefficient of intrinsic coercivity $(b=-0.52 \Delta T$ for $\mathrm{UH}$ magnet type) and $d$ is the model depth, which equals to outer-to-inner radius difference.

The saturable reluctances of stator and brake disc are defined as functions of magnetic field strength in the network model. For example, the stator yoke reluctance is defined as

$\mathfrak{R}_{\mathrm{x} 0-1, \mathrm{y}, \mathrm{l}-1}=\frac{I I_{\mathrm{x} 0-1, \mathrm{y} 0 \mathrm{-1}}(B(T))}{B_{\mathrm{x} 0-1, \mathrm{y} 0 \mathrm{l}-1}(T)} \frac{x_{1}-x_{0}}{\left(y_{2}-y_{1}\right) d}$.

Magnetic properties of low carbon steel depend on temperature, $B(T)$ and $H(T)$ which are given in the Appendix [17]. The saturable reluctances are expressed as functions of $H$ since the nonlinear analysis converges the solution faster with this approach. The $H B$-curve of the low carbon steel used here is presented in Fig. 4.

The Newton-Raphson method is used as a nonlinear solver for the reluctance network modeling. The Newton-Raphson method may have converging problems when the model has numerous initial parameters. Because of the selection of arbitrary initial parameters, the model could have nontrivial dynamics. The reluctance network model given in Fig. 3-(b) has the number of 37 saturable reluctances and classical NewtonRaphson method cannot converge a solution.

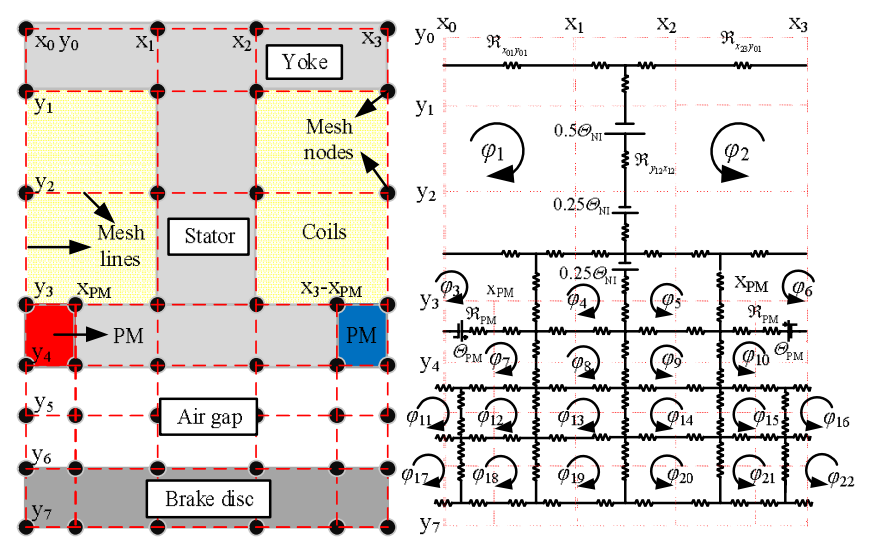

(a)

(b)

Fig. 3. (a) 2D symmetry model of the proposed AF-PMA-ECB with mesh nodes and mesh lines and (b) reluctance network model of the proposed AF-PMAECB. The current linkage $\Theta$ is divided in three proportions. The coordinates of $y_{5}$ and $y_{6}$ are not shown for better view.

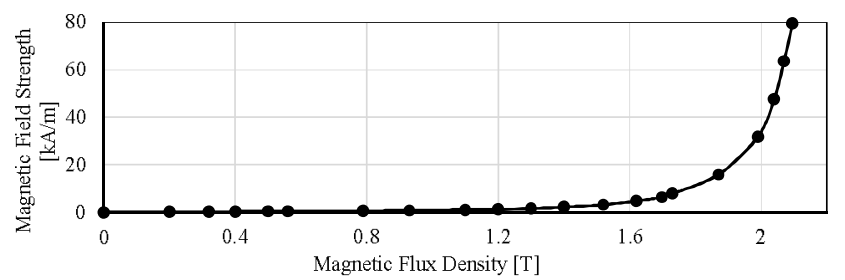

Fig. 4. $H B$-curve of the low carbon steel (ST37)

Therefore, the Newton-Raphson method is relaxed by

$$
x_{i+1}=x_{i}-\alpha_{i} \frac{f_{i}(x)}{\operatorname{sign}\left(f_{i}^{\prime}(x)\right) a b s\left(f_{i}^{\prime}(x)\right)}
$$

where $i$ is the iteration number, $\alpha$ is the relaxation factor, which is set to 0.5 in this study. The aim of this modification is to follow the derivative of the function to assign the slope sign into the convergence problem. The Newton-Raphson method is an iteration-based root finding algorithm which starts with the initialization of magnetic flux densities and fluxes. Next step, magnetic fields are obtained based on $H B$-curve and then the reluctances are calculated. Following, functions and theirs derivatives are computed and mesh fluxes are calculated. As a last computational step, magnetic flux densities are calculated and comparison is performed. In each iteration, saturable reluctances are updated by the $H B$-curve until the desired error is obtained. One has to point out that the $H B B$-curve is preferred since it is more suitable for the Newton-Raphson functions derivatives than the $B H$-curve

The important stage of the Newton-Raphson method is the calculation of functions and their derivatives. As seen in Fig. 3(b), the mesh fluxes have symmetry so that the $1^{\text {st }}$ flux mesh is equal to the $2^{\text {nd }}$ flux mesh and the $3^{\text {rd }}$ flux mesh is equal to the $6^{\text {th }}$ flux mesh and etc. Therefore, the definition of the left-side or the right-side Newton-Raphson functions and derivatives is adequate for the entire model. The $1^{\text {st }}$ function and its derivative are described as

$$
\begin{aligned}
& f_{1}=\varphi_{1} \Re_{1}+\varphi_{2} \Re_{1-2}-\varphi_{3} \Re_{1-3}-\varphi_{4} \Re_{1-4}+0.75 \Theta_{\mathrm{NI}} \\
& \frac{\partial f_{1}}{\partial \varphi_{1}}=\Re_{1}+\varphi_{1} \frac{\partial \Re_{1}}{\partial \varphi_{1}}+\varphi_{2} \frac{\partial \Re_{1-2}}{\partial \varphi_{1}}+\varphi_{4} \frac{\partial \Re_{1-4}}{\partial \varphi_{1}}
\end{aligned}
$$

where $\varphi$ is the mesh flux, $\mathfrak{R}_{1}$ notation represents the sum of the 
reluctances in the first mesh flux while $\mathfrak{R}_{1-2}$ notation represents the mutual reluctances of $1^{\text {st }}$ and $2^{\text {nd }}$ mesh fluxes. The other functions and their derivatives are described in similar manner. At the end of Newton-Raphson method, magnetic flux densities for all reluctances and skip depth are calculated.

Static air gap magnetic flux density variation is defined as [18]

$$
B_{\mathrm{s}}(\theta)=\left\{\begin{array}{cc}
B_{\mathrm{a}} e^{(\theta-0.5 \beta) / g}, & -\pi / 2 p<\theta<-0.5 \beta \\
B_{\mathrm{a}}, & -0.5 \beta \leq \theta \leq 0.5 \beta \\
B_{\mathrm{a}} e^{(-\theta-0.5 \beta) / g}, & 0.5 \beta<\theta<\pi / 2 p
\end{array}\right.
$$

where $\theta$ is electrical brake disc position, $p$ is the number of pole pairs, $\beta=\pi\left(\mathrm{x}_{3}-2 \mathrm{x}_{\mathrm{PM}}\right) / \mathrm{x}_{3} p$ and $B_{\mathrm{a}}$ is the amplitude of the air gap magnetic flux density which is defined as

$$
B_{\mathrm{a}}=\left(B_{y j-4, x 1-\mathrm{PM}}+B_{y 5-6, x 1-\mathrm{PM}}\right) / 2
$$

The dynamic magnetic field in the air gap consists of static magnetic field and the induced magnetic field defined by [19], [20]

$$
B_{\mathrm{d}}(\theta)=B_{\mathrm{s}}(\theta)+B_{\mathrm{i}}(\theta)
$$

where $B_{\mathrm{i}}$ is induced magnetic flux density by eddy currents. According to Faraday's Law, the induced current density is written as

$$
J(r, \theta)=\sigma(T) r \omega B_{\mathrm{d}}(\theta)
$$

(9)

where $\sigma(T)$ is conductivity of the brake disc as a function of temperature (given in the Appendix), $r$ is the mean radius and $\omega$ is the angular speed. Based on Ampere's Law, the current linkage generated by eddy current path can be explained by

$$
\oint H \mathrm{~d} l=\int_{\theta_{1}}^{\theta_{2}} \int_{0}^{\delta} J(r, \theta) r \mathrm{~d} z \mathrm{~d} O
$$

where $\delta$ is the skin depth defined by

$$
\delta=\sqrt{\frac{2 H_{0}}{\sigma(T) \omega B_{\mathrm{st}}\left(H_{0}, T\right)}}
$$

where $H_{0}$ is the peak value of applied surface magnetic field and $B_{\text {st }}$ is the saturation value of magnetic flux density. It should be pointed out that contrary to the classical skin depth theory for nonsaturating materials, if time varying magnetic field is applied to conductive region, the magnetic flux density will be either $-B_{\text {st }}$ or $+B_{\text {st. }}[21]$, [22].

The permeability of the stator and the brake disc is much greater than the air gap. Therefore, the current linkage drops of these parts can be neglected. Thus, (10) can be expressed by

$$
B_{i}(\theta)=m \int_{\theta_{1}}^{\theta_{2}}\left(B_{\mathrm{s}}(\theta)+B_{\mathrm{i}}(\theta)\right) \mathrm{d} \theta
$$

where $m$ is $\mu_{0} \sigma(T) \omega \delta r^{2} / 2 g$. Differentiating (12) with respect to the brake disc position, $\theta$, the below differential formula is obtained.

$$
\frac{\mathrm{d} B_{\mathrm{i}}(\theta)}{\mathrm{d} \theta}-m B_{\mathrm{i}}(\theta)-m B_{\mathrm{s}}(\theta)=0 \text {. }
$$

(13)

General solution of $B_{\mathrm{i}}$ can be derived as

$$
B_{\mathrm{i}}(\theta)=\left\{\begin{array}{lc}
e^{m \theta} c_{1}+e^{m \theta} \frac{a m B_{\mathrm{a}} e_{1}}{-1+a m}, & -\pi / 2 p<\theta<-0.5 \beta \\
e^{m \theta} c_{2}+e^{m \theta} B_{a} e_{2}, & -0.5 \beta \leq \theta \leq 0.5 \beta . \\
e^{m \theta} c_{3}+e^{m \theta} \frac{a m B_{\mathrm{a}} e_{3}}{1+a m}, & 0.5 \beta<\theta<\pi / 2 p
\end{array}\right.
$$

where the parameters of $e_{1}, e_{2}$ and $e_{3}$ are given in the Appendix. According to Ampere's Law, the total current is equal in the intervals $\left[-\pi / 2 p, \theta_{0}\right]$ and $\left[\theta_{0}, \pi / 2 p\right]$ defined as

$$
\int_{-\pi / 2}^{\theta_{0}} \int_{0}^{\delta} J(r, \theta) r \mathrm{~d} z \mathrm{~d} \theta=\int_{\theta_{0}}^{\pi / 2 p} \int_{0}^{\delta} J(r, \theta) r \mathrm{~d} z \mathrm{~d} \theta
$$

where $\theta_{0}$ is an special point where $e^{m \theta} c_{2}+e^{m \theta} B_{a} e_{2}=0$. Other interface conditions are defined by

$$
\begin{array}{ll}
e^{m \theta} c_{2}+e^{m \theta} B_{a} e_{2}=e^{m \theta} c_{1}+e^{m \theta} \frac{a m B_{a} e_{1}}{-1+a m}, & \theta=-0.5 \beta \\
e^{m \theta} c_{2}+e^{m \theta} B_{a} e_{2}=e^{m \theta} c_{3}+e^{m \theta} \frac{a m B_{a} e_{3}}{1+a m}, & \theta=0.5 \beta
\end{array}
$$

The coefficients of $c_{1}, c_{2}$, and $c_{3}$ are obtained by solving the interface conditions and defined by

$$
\begin{aligned}
& c_{1}=B_{a}\left(e^{-m \theta_{0}}+\frac{e^{m 0.5 \beta}-a m e^{\frac{-(\pi / 2)+a m(\pi / 2)+0.5 \beta p}{a p}}}{a m-1}\right) \\
& c_{2}=B_{a}\left(e^{-m \theta_{0}}-e^{m 0.5 \beta}\right) \\
& c_{3}=B_{a}\left(e^{-m \theta_{0}}-e^{-m 0.5 \beta}\right)
\end{aligned}
$$

By solving (15) with interface conditions, $\theta_{0}$ is calculated as $\theta_{0}=-m^{-1} \ln \left(\cosh \left(\frac{m \pi}{2 p}-m 0.5 \beta\right) / \cosh \left(\frac{m \pi}{2 p}\right)\right)$

Finally, dynamic air gap magnetic flux density is defined by

$$
B_{\mathrm{d}}(\theta)=\left\{\begin{array}{lr}
\frac{B_{\mathrm{a}} e^{-m \theta_{0}} d_{1}}{a m-1}, & -\pi / 2 p<\theta<-0.5 \beta \\
B_{\mathrm{a}} e^{m\left(\theta-\theta_{0}\right)}, & -0.5 \beta \leq \theta \leq 0.5 \beta \\
\frac{B_{\mathrm{a}} d_{2}}{a m+1}, & 0.5 \beta<\theta<\pi / 2 p
\end{array}\right.
$$

where the parameters of $d_{1}$ and $d_{2}$ are defined by

$d_{1}=e^{-m\left(\theta+\theta_{0}+0.5 \beta\right)}-e^{\left(0.5 \beta+a m \theta_{0}+\theta\right) / a}+e^{m \theta}(a m-1)$

$d_{2}=e^{(0.5 \beta-\theta) / a}-e^{k(-0.5 \beta+\theta)}+e^{m\left(\theta-\theta_{0}\right)}(a m+1)$

After the dynamic air gap magnetic flux density is obtained, the braking power can be calculated by

$$
\begin{aligned}
P_{\mathrm{br}} & =\frac{1}{\sigma(T)} \int_{-\pi / 2 p}^{\pi / 2 p} \int_{0}^{\delta} \int_{r_{\mathrm{i}}}^{r_{\mathrm{o}}} J(r, O)^{2} r \mathrm{~d} r \mathrm{~d} z \mathrm{~d} \theta \\
& =\frac{1}{\sigma(T)} \int_{-\pi / 2 p}^{\pi / 2 p} \int_{0}^{\delta} \int_{r_{\mathrm{i}}}^{r_{0}}\left[\sigma(T) r \omega\left(B_{\mathrm{s}}(T)+B_{\mathrm{i}}(T)\right)\right]^{2} r \mathrm{~d} r \mathrm{~d} z \mathrm{~d} \theta
\end{aligned}
$$

where $r_{\mathrm{i}}$ and $r_{\mathrm{o}}$ are inner and outer radius respectively. Finally, the braking torque is obtained by

$T_{\mathrm{br}}=P_{\mathrm{br}} / \omega$ 


\section{B. Thermal Analysis}

Thermal analysis of the proposed $A F-P M A-E C B$ is performed by nonlinear $3 \mathrm{D}$ thermal lumped parameter model. The braking power calculated in the magnetic analysis is used as an input in the thermal analysis. The schematic drawing and thermal resistance network of the proposed $\mathrm{ECB}$ are given in Fig. 5. Due to the AF geometry and 3D temperature flow, Tequivalent circuit modeling is preferred [23], [24]. The thermal network consists of eleven nodes: 1) disc, 2) air gap, 3) PM, 4) teeth tips, 5) stator teeth, 6) slot windings, 7) yoke, 8) frame and 9-10-11) shaft.

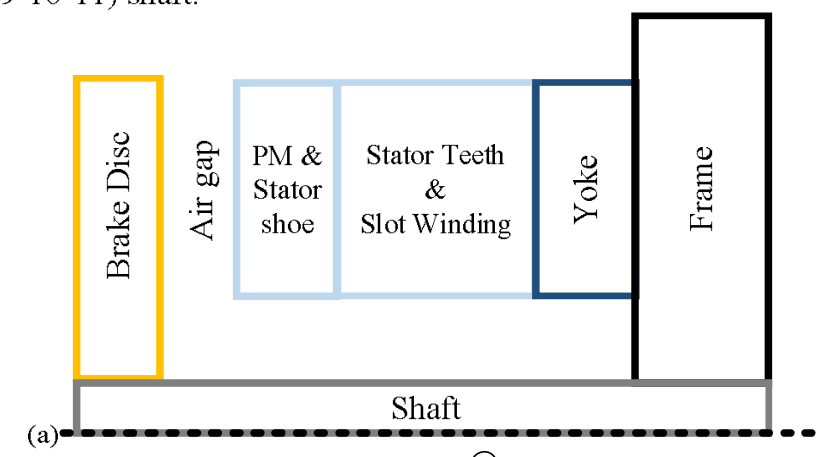

(b)

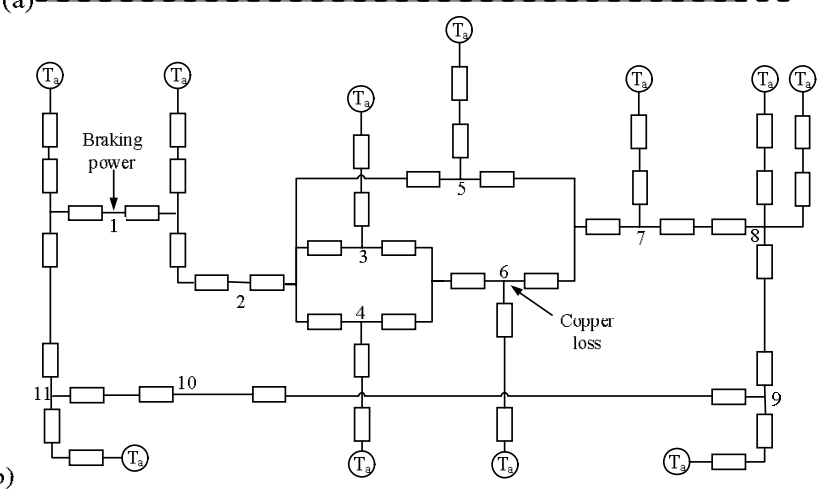

Fig. 5. (a) The schematic drawing and (b) thermal resistance network of the proposed AF-PMA-ECB. $T_{a}$ represents the ambient temperature.

For the transient analysis, the temperature rise of each node is calculated with the matrix equation defined as

$\frac{\mathrm{d}}{\mathrm{d} t}(\Delta \mathbf{T})=\mathbf{C}^{-1}(\mathbf{P}-\mathbf{G} \cdot \Delta \mathbf{T})$

where $t$ is the time, $\Delta \mathbf{T}$ is the temperature rise vector, $\mathbf{C}$ is the thermal capacitance matrix, $\mathbf{P}$ is the power loss vector and $\mathbf{G}$ is the thermal conductance matrix. The thermal capacitance matrix is defined by

$$
\mathrm{C}=\left[\begin{array}{ccccc}
C p_{1} & 0 & 0 & \cdots & 0 \\
0 & C p_{2} & 0 & \cdots & 0 \\
0 & 0 & C p_{3} & \cdots & 0 \\
\vdots & \vdots & \vdots & \ddots & \vdots \\
0 & 0 & 0 & \cdots & C p_{\mathrm{n}}
\end{array}\right]
$$

where $\mathrm{n}$ is the node number and $\mathrm{C}$ is the thermal capacitance of an element defined by

$$
\boldsymbol{C p}=c(T) \rho_{\mathrm{d}}(T) V
$$

where $c$ is the specific heat, $\rho_{\mathrm{d}}$ is the mass density (given in the Appendix) and $V$ is the volume. The power loss vector is defined by

$$
P=\left[\begin{array}{lllll}
P_{1} & \cdots & P_{6} & \cdots & P_{\mathrm{Il}}
\end{array}\right]
$$

Here, $P_{1}$ is braking power calculated in (25) and $P_{6}$ is the copper loss defined by

$$
P_{\mathrm{Cu}}=J^{2} A_{\mathrm{Cu}} l_{\mathrm{Cu}} \rho_{\mathrm{Cu}}(T)
$$

where $\underline{A}_{\mathrm{Cu}}$ is the cross sectional area of the copper, $l_{\mathrm{Cu}}$ is total length of the copper wire and $\rho_{\mathrm{Cu}}$ is the resistivity of copper (given in the Appendix). The thermal conductance matrix is defined by

$$
G=\left[\begin{array}{ccccc}
\sum_{i=1}^{n} \frac{1}{R_{1,1}} & -\frac{1}{R_{1,2}} & -\frac{1}{R_{1,3}} & \cdots & -\frac{1}{R_{1, n}} \\
-\frac{1}{R_{2,1}} & \sum_{\mathrm{i}=1}^{\mathrm{n}} \frac{1}{R_{2,1}} & -\frac{1}{R_{2,3}} & \cdots & -\frac{1}{R_{2, n}} \\
-\frac{1}{R_{3,1}} & -\frac{1}{R_{3,2}} & \sum_{\mathrm{i}=1}^{\mathrm{n}} \frac{1}{R_{3,1}} & \cdots & -\frac{1}{R_{3, n}} \\
\vdots & \vdots & \vdots & \ddots & \vdots \\
-\frac{1}{R_{n, 1}} & -\frac{1}{R_{n, 2}} & -\frac{1}{R_{n, 3}} & \cdots & \sum_{i=1}^{m n} \frac{1}{R_{n, j}}
\end{array}\right]
$$

Here, $R$ is the thermal resistance. The subscripts in $R$ define the total thermal resistance between the two nodes. In the nonlinear thermal modelling, conduction and convection are considered and radiation is neglected. The conductive and convective thermal resistances are defined by

$$
\begin{aligned}
& R=\frac{l}{\lambda(T) S} \\
& R_{\text {corr }}=\frac{1}{h A}
\end{aligned}
$$

where $l$ is the length of the heat flow, $\lambda$ is the thermal conductivity (parameters are given in the Appendix), $h$ is the convection coefficient, $S$ is the cross-sectional area. The convection coefficient in the air gap between the brake disc and stator is calculated by

$h_{\text {air }}=\frac{N u \hat{\lambda}_{\text {air }}}{g}$

where $\lambda_{\text {air }}$ is the thermal conductivity of air and $N u$ is the Nusselt numbers. The convection coefficient between the brake disc and the ambient has radial and axial directions. The convection coefficient in axial direction is calculated by the following set of equations [23], [24]

$$
\begin{aligned}
& h_{\mathrm{ax}}=\frac{N u_{\mathrm{ax}} \lambda_{\mathrm{air}}}{r_{\mathrm{o}}} \\
& N u_{\mathrm{ax}}=\frac{\operatorname{Pr} \operatorname{Re}_{\mathrm{ax}} C m_{\mathrm{ax}}}{2 \pi} \\
& \text { Laminar Flow }\left(R e_{\mathrm{ax}}<3 \times 10^{5}\right), C m_{\mathrm{ax}}=\frac{3.87}{R e_{\mathrm{ax}}^{0.5}} \\
& \text { Turbulent Flow }\left(R e_{\mathrm{ax}}>3 \times 10^{5}\right), C m_{\mathrm{ax}}=\frac{0.146}{R e_{\mathrm{ax}}^{0.2}}
\end{aligned}
$$

where, $R e$ is the Reynolds number, $C m_{\mathrm{ax}}$ is the axial flow coefficient and $P r$ is the average Prandt number. The convection coefficient in radial direction is calculated by the following set of equations 
$G r=\frac{\rho_{\mathrm{da}}^{2} F_{\mathrm{g}} \beta_{\mathrm{c}} \Delta T\left(L_{\mathrm{c}}\right)^{3}}{\mu_{\mathrm{d}}^{2}}$

$N u_{\mathrm{rad}}=0.18\left(\operatorname{Pr}\left(0.5 \operatorname{Re}_{\mathrm{rad}}^{2}+G r\right)\right)^{0.315}$

where $G r$ is the Grashof number, $\rho_{\mathrm{d}}$ a is the mass density of the air, $F_{\mathrm{g}}$ is the gravitational attraction force, $\beta_{\mathrm{c}}$ coefficient of cubical expansion, $L_{\mathrm{c}}$ is the characteristic length. Finally, the convection coefficient in radial direction is defined as

$h_{\mathrm{rad}}=\frac{N u_{\mathrm{rad}} \lambda_{\mathrm{air}}}{2 r_{\mathrm{o}}}$

The thermal analysis has two inputs as the braking loss and the copper loss and starts with setting the initial parameters. The coefficients are derived by current temperature value and (26) is solved to calculate the temperature rise for each nodes. The critical temperature of the brake disc and the magnets are checked and if either is larger than the desired value, the analy sis is stopped. If not, the calculated temperature data is shared with the magnetic analysis.

\section{3D-FEA OF THE AF-PMA-ECB}

Electromagnetic 3D-FEA of the AF-PMA-ECB is investigated to prove the proposed magnetic analysis. The symmetric 3D-FE model, mesh structure and magnetic flux density profile for maximum excitation current of 7.7A DC (equals to $10 \mathrm{~A} / \mathrm{mm}^{2}$ in the coil) are given in Fig. 6. Air gap is meshed with 2 layers to increase the accuracy of analyses. The magnetic flux density value of the yoke, the tooth and the brake disc are also illustrated in the figure. The comparison of the magnetic flux density values obtained from 3D-FEA and the proposed static magnetic analysis is summarized in Table II. Close results are obtained between the 3D-FEA and the proposed static magnetic analysis even in the saturation region.
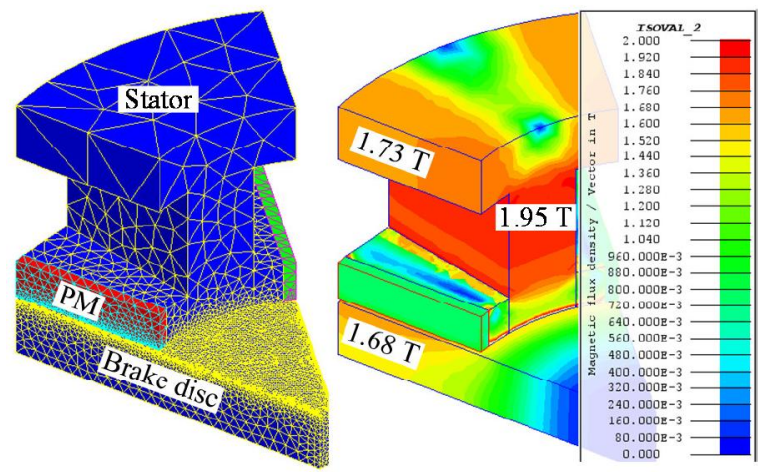

Fig. 6. 3D-FE model, mesh structure and magnetic flux density profile of the AF-PMA-ECB for 7.7 A DC excitation current at the time zero.

TABLE II

COMPARISON OF RESULTS OBTAINED FROM 3D-FEA AND STATIC MAGNETIC

\begin{tabular}{cccc}
\multicolumn{3}{c}{ ANALYsis } \\
\hline & Yoke & Tooth & Brake Disc \\
\hline Magnetic Analysis & $1.77 \mathrm{~T}$ & $1.88 \mathrm{~T}$ & $1.65 \mathrm{~T}$ \\
3D-FEA & $1.73 \mathrm{~T}$ & $1.95 \mathrm{~T}$ & $1.68 \mathrm{~T}$ \\
\hline \hline
\end{tabular}

The key component to ealculate the braking torque is definitely the air gap magnetic flux density variation. In ECBs, the air gap magnetic flux density alters by the speed because of armature reaction phenomenon. The influence of armature reaction on the air gap magnetic flux density has a great impact on braking torque. To verify the proposed magnetic analysis, 3D-FEAs are carried out for various speeds $(500,1000$ and $2000 \mathrm{~min}^{-1}$ ) at maximum excitation current. Air gap magnetic flux density variations obtained from 3D-FEA and proposed magnetic analysis are given in Fig. 7. The static air gap magnetic flux density variation is given in Fig. 7-(a) and the magnetic flux density variations obtained from proposed approach and 3D-FEA are in perfect agreement. Air gap magnetic flux density variations at the speeds of 500, 1000 and $2000 \mathrm{~min}^{-1}$ are provided in Fig. 7-(b-c-d). Air gap flux density variations obtained from magnetic analysis are in good agreement with 3D-FEA results. The effect of armature reaction is getting dominant as the speed is increased and it is clearly seen by the figure. The average magnetic flux density values are given in Table III. The average magnetic flux density values obtained from analytical analysis and 3D-FEA are in bigh harmony. As the speed is increased, the average magnetic flux density closes to zero. It can be stated that the proposed magnetic analysis provides practical dynamic air gap magnetic flux density variation.

TABLE III

AVERAGE MAGNETIC FLUX DENSITY VALUE OBTAINED FROM 3D-FEA AND MAGNETIC ANALYSIS

\begin{tabular}{ccccc}
\hline & $0 \mathrm{~min}^{-1}$ & $500 \mathrm{~min}^{-1}$ & $1000 \mathrm{~min}^{-1}$ & $2000 \mathrm{~min}^{-1}$ \\
\hline Magnetic Analysis & $0.95 \mathrm{~T}$ & $0.68 \mathrm{~T}$ & $0.46 \mathrm{~T}$ & $0.37 \mathrm{~T}$ \\
3D-FEA & $0.90 \mathrm{~T}$ & $0.64 \mathrm{~T}$ & $0.466 \mathrm{~T}$ & $0.36 \mathrm{~T}$ \\
\hline \hline
\end{tabular}
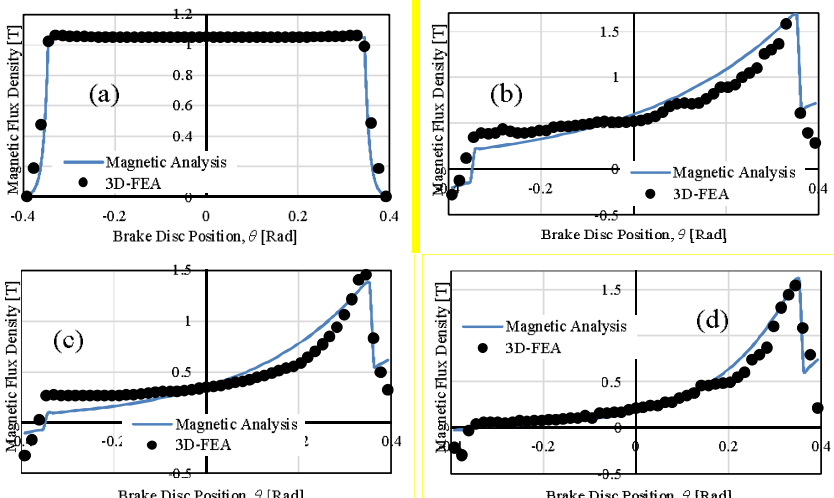

Fig. 7. Dynamic air gap magnetic flux density variations obtained from magnetic analysis and 3D-FEA at (a) zero speed, (b) the speed of 500 $\mathrm{min}^{-1}$, (c) the speed of $1000 \mathrm{~min}^{-1}$ and (d) the speed of $2000 \mathrm{~min}^{-1}$.

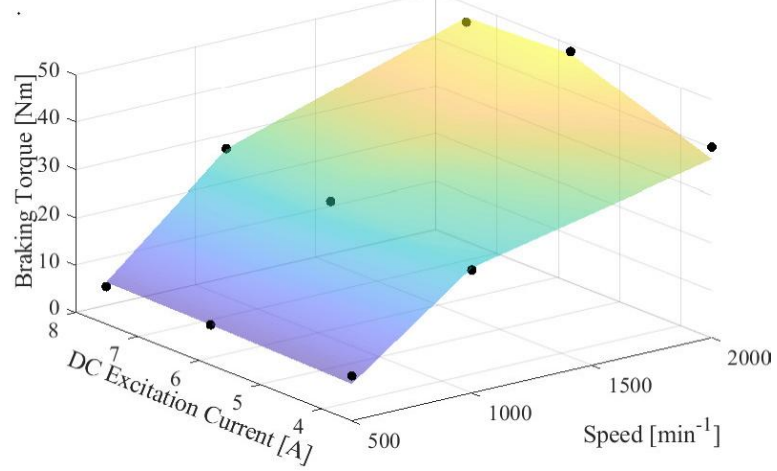

Fig. 8. Braking torque profile of the brake for various speeds and excitation currents. The black points represent the $3 \mathrm{D}$-FEA results. 
Various simulations are also performed at different speeds $\left(500,1000\right.$ and $\left.2000 \mathrm{~min}^{-1}\right)$ and excitation currents $(3.5,5.8 \mathrm{~A}$ DC) so as to obtain the braking torque profile for validation. The braking profile obtained from proposed magnetic analysis approach is given in Fig. 8. 3D-FEAs results are also provided in the figure with black spots and it is seen that the proposed approach works extremely well for the proposed ECB system.

\section{Prototype, Test Setup and Experimental STUDIES}

The prototype of the investigated AF-PMA-ECB was manufactured and is illustrated in Fig. 9 where stator with magnets, windings and the brake disc are clearly seen. The same parameters provided in Table I are used in the prototype ECB. The prototype has 180-to-100 $\mathrm{mm}$ outer-to-inner diameter. ST37, low carbon steel, material is used as the stator core and the brake disc material in the prototype. The manufactured brake disc has $15 \mathrm{~mm}$ thickness and outer diameter of $180 \mathrm{~mm}$. Concentrated windings are employed and connected in series. N30UH type magnets were glued in the slot openings.

The test setup with temperature measuring and capturing tools is displayed in Fig. 10. The test setup consists of a drive motor, a prototype and a torque meter. The drive motor has 47.5 $\mathrm{Nm}$ rated torque with $3000 \mathrm{~min}^{-1}$ of maximum speed. The torque meter has 0-50 $\mathrm{Nm}$ torque range with high accuracy. Thermal camera is used in the test system to capture the thermal images of the prototype during braking. During the tests, a thermal camera is located exactly in the same place as shown in the figure. The approximate distance is about $120 \mathrm{~cm}$. A thermocouple is also attached to the magnet surface by special thermal paste and two laser-spot infrared thermometers are used to measure the temperature rise in the brake disc and the PM. The dSPACE control board is also used in the system to record the temperature rise, excitation current variation and the braking torque variations.
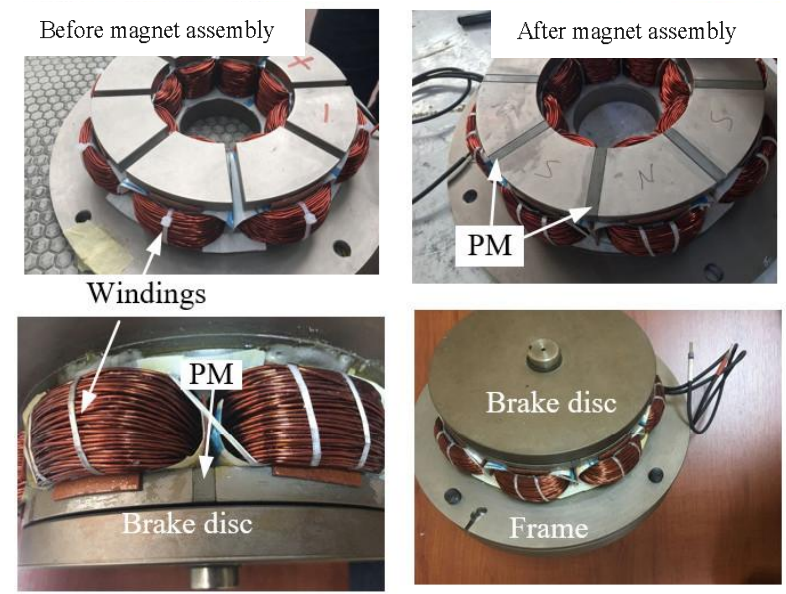

Fig. 9. Prototype of the investigated AF-PMA-ECB.

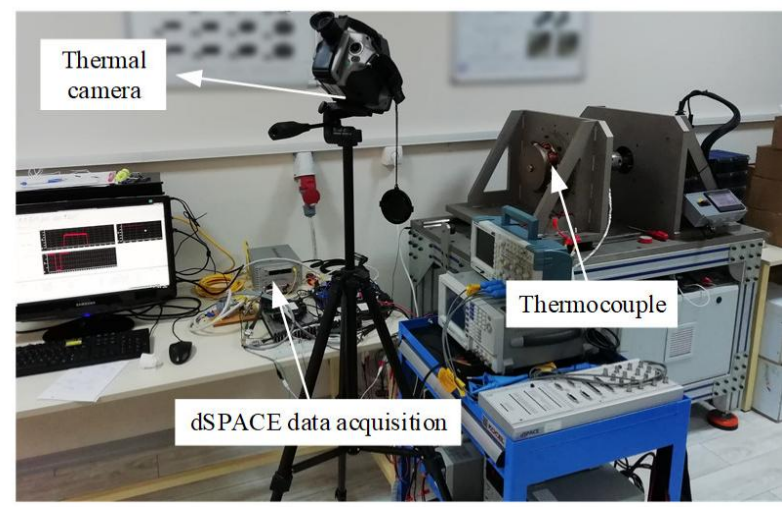

Fig. 10. Test setup with temperature measuring and capturing tools.

Six different test scenarios are explored during the tests. The studied experimental cases are shown in Table IV. The excitation current is fixed in the first 3 scenarios ( $A, B$ and $C$ ), while the excitation current is varied with temperature rise in scenarios $\mathrm{D}, \mathrm{E}$ and $\mathrm{F}$. The maximum temperature for the brake disc is limited to $160^{\circ} \mathrm{C}$, for the magnets it is limited to $120^{\circ} \mathrm{C}$ during the tests. The magnets used in the prototype have maximum working temperature of $180^{\circ} \mathrm{C}$.

TABLE IV

\begin{tabular}{ccc}
\multicolumn{3}{c}{ SCENARIOS FOR THE PROPOSED ANAL YSIS APPROACH } \\
\hline Scenario & Speed $\left[\mathrm{min}^{-1}\right]$ & Current $[A]$ \\
\hline A & 1000 & 7.7 A fixed \\
B & 1000 & 5.8 A fixed \\
C & 1000 & 3.5 A fixed \\
D & 500 & 7.7 A at the initial \\
E & 1000 & 7.7 A at the initial \\
F & 2000 & 7.7 A at the initial \\
\hline
\end{tabular}
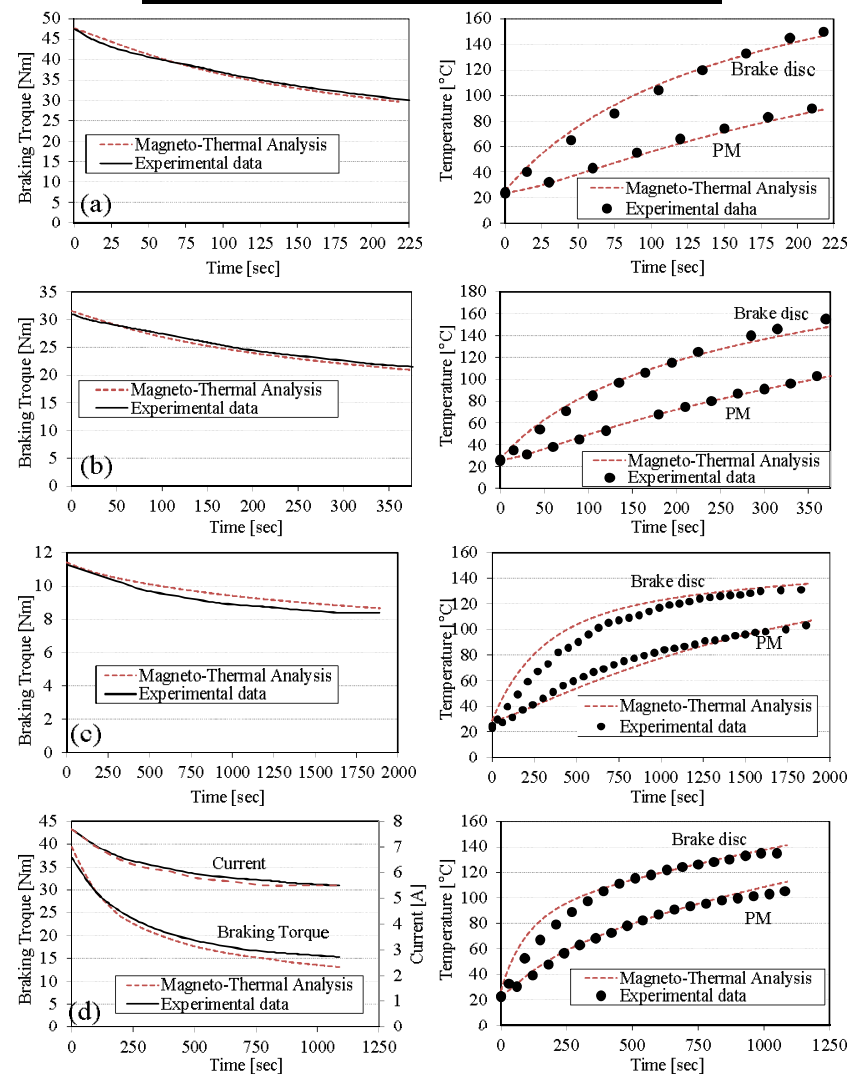

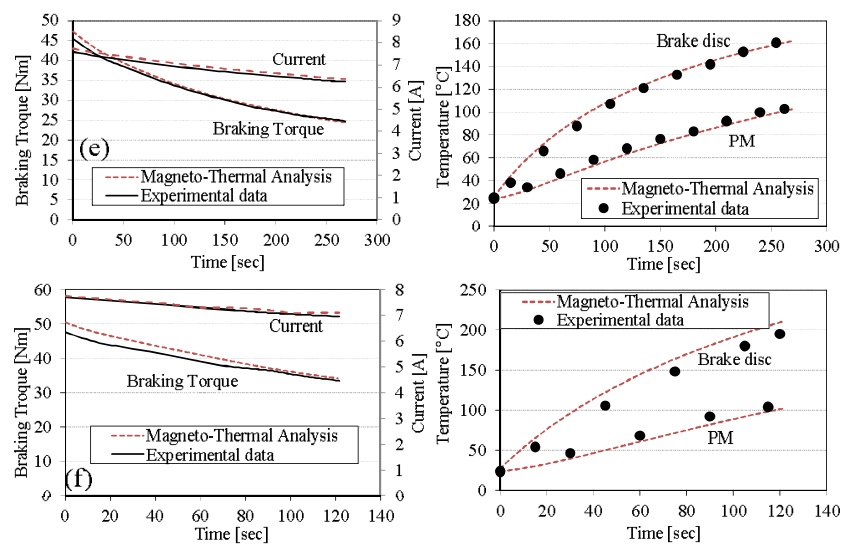

Fig. 11. Braking torque and temperature variation for (a) Scenario- $A$, (b) Scenario-B, (c) Scenario-C, (d) Scenario-D, (e) Scenario-E and (f) Scenario-F. (Current variation is valid for Scenario-D-E-F.)

Braking torque and temperature variations for all scenarios are provided in Fig. 11. Generally speaking, the results obtained from the experiments and the proposed coupled magnetothermal analysis are in good agreement. The following comments are drawn from the experiments:

- Scenario-A (Fig. 11-a): The braking torque is initially 47.5 $\mathrm{Nm}$ and is reduced to $30 \mathrm{Nm}$ after $225 \mathrm{~s}$. The brake disc temperature rise is $128.7^{\circ} \mathrm{C}$ and the permanent magnet temperature rise is $77.7^{\circ} \mathrm{C}$ after $225 \mathrm{~s}$. The ECB can work nearly $225 \mathrm{~s}$ with this scenario

- Scenario-B (Fig. 11-b): The braking torque is reduced from $31 \mathrm{Nm}$ to $21.5 \mathrm{Nm}$ after $376 \mathrm{~s}$. The temperature rise for the brake dise is $129^{\circ} \mathrm{C}$ and for the magnets it is $77.7^{\circ} \mathrm{C}$. The ECB can run approximately $376 \mathrm{~s}$ with this scenario.

- Scenario-C (Fig. 11-c): Initially $11.3 \mathrm{Nm}$ of braking torque is reduced to $8.4 \mathrm{Nm}$ after $1890 \mathrm{~s}$. The temperature rise for the brake dise is $106^{\circ} \mathrm{C}$ and for the magnets it is $80^{\circ} \mathrm{C}$. The proposed AF-PMA-ECB can work approximately $2000 \mathrm{~s}$ in this scenario.

- Scenario-D (Fig. 11-d): The braking torque is initially 37.7 $\mathrm{Nm}$ and reduced to $15.3 \mathrm{Nm}$ after $1088 \mathrm{~s}$. The brake disc temperature rise is $112.5^{\circ} \mathrm{C}$ and the magnets temperature rise is $82.5^{\circ} \mathrm{C}$ after $1088 \mathrm{~s}$. The excitation current is reduced by $28.6 \%$ during this period. The proposed ECB can run nearly $1100 \mathrm{~s}$ with this scenario.

- Scenario-E (Fig. 11-e): $45.5 \mathrm{Nm}$ of braking torque at the beginning is reduced to $24.8 \mathrm{Nm}$ after $270 \mathrm{~s}$. The temperature rise for the disc is $136{ }^{\circ} \mathrm{C}$ and for the magnets it is $80^{\circ} \mathrm{C}$. The reduction of the excitation current is $17.7 \%$. The brake can work approximately $270 \mathrm{~s}$ in this scenario.

- Scenario-F (Fig. 11-f): The braking torque is initially 47.5 $\mathrm{Nm}$ and is reduced to $33.4 \mathrm{Nm}$ after $121 \mathrm{~s}$. The temperature rise for the brake is $171^{\circ} \mathrm{C}$ and for the magnets it is $81^{\circ} \mathrm{C}$. The excitation current reduction is $8.4 \%$. The brake can operate approximately $100 \mathrm{~s}$ with this scenario. Thermal images of the prototype during Scenario-F operation are captured to check the proposed analy sis approach (Fig. 12). The thermal images are taken in the beginning of the test, after 40,74 and 120 seconds of braking, respectively. It is observed that the temperature values obtained from the thermal images agree well with the results of the proposed coupled magneto-thermal analysis approach.

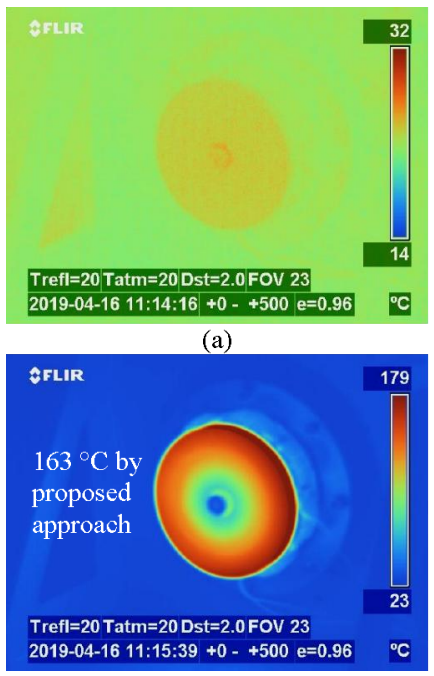

(c)

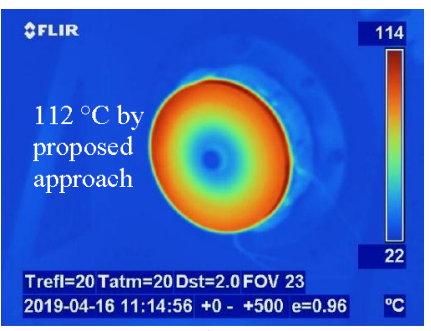

(b)

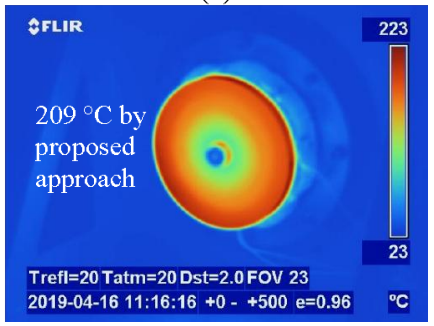

(d)
Fig. 12. Thermal image of the prototype for Scenario-F: (a) in the beginning, (b) after 40 seconds, (c) after 74 seconds and (d) after 120 seconds of braking.

The proposed approach results are also given in Table V. To give some comparison; the braking torque reduction percentage for Scenario- $A$ is calculated to be $37.64 \%$ by the proposed approach while the experimental reduction was $36.8 \%$. The temperature rise in the brake disc for Scenario-D is calculated to be $104{ }^{\circ} \mathrm{C}$ by the proposed approach and was found to be $112.5^{\circ} \mathrm{C}$ during experiments. The temperature rise in the magnets for Scenario- $F$ was obtained to be $78{ }^{\circ} \mathrm{C}$ by the proposed approach and $81{ }^{\circ} \mathrm{C}$ found in the experiments. It has to be marked that the braking torque obtained from the proposed approach is nearly $7.5 \%$ lower with respect to the experiment results in the beginning of Scenario-F. The main reason for the error is the high rotational speed and the $3 \mathrm{D}$ armature effect owing to the physical structure of the brake disc. Overall, it can be stated that the proposed approach works well in determining the total braking time and the temperature rise in the brake disc and the magnets.

TABLE V

\begin{tabular}{cccccc}
\multicolumn{5}{c}{ PERFORMANCE OF SCENARIOS BASED ON PROPOSED APPROACH } \\
\hline \hline Scenario & $\begin{array}{c}\text { Braking } \\
\text { Time }\end{array}$ & $\begin{array}{c}\text { Braking } \\
\text { Torque } \\
\text { Reduction } \%\end{array}$ & $\begin{array}{c}\text { Current } \\
\text { Reduction } \\
\%\end{array}$ & $\begin{array}{c}\text { Temperature } \\
\text { Rise in Brake } \\
\text { Disc }\end{array}$ & $\begin{array}{c}\text { Temperature } \\
\text { Rise in } \\
\text { Magnets }\end{array}$ \\
\hline A & $225 \mathrm{~s}$ & $37.64 \%$ & - & 121.37 & 64.95 \\
B & $376 \mathrm{~s}$ & $33.7 \%$ & - & 121 & 76 \\
C & $1890 \mathrm{~s}$ & $24.1 \%$ & - & 107 & 78.3 \\
D & $1088 \mathrm{~s}$ & $66.8 \%$ & $28.6 \%$ & 104 & 88.7 \\
E & $270 \mathrm{~s}$ & $48.2 \%$ & $17.7 \%$ & 137 & 78.5 \\
F & $121 \mathrm{~s}$ & $32.4 \%$ & $8.4 \%$ & 183 & 78 \\
\hline \hline
\end{tabular}

\section{CONCLUSIONS}

In this paper, a new analytic magneto-thermal analysis approach is proposed for AF-PMA-ECB to define the working limitations at high temperature conditions. The proposed coupled analysis is a simple and effective approach and is an alternative option to time-consuming and complex multiphysics FEA software. A prototype AF-PMA-ECB was built and tested for several test scenarios. The results indicate that the proposed approach works well and provides very fast solutions compared 
to complex FEA simulations. The total operating time, maximum temperature rise and braking torque variation can accurately be predicted by the proposed approach. It can also be stated that the proposed approach can be implemented to any kind of PM-based electrical machine at high temperature conditions provided that magnetic modeling is modified based on magnetic and thermal modeling should be revised by the machine geometry.

$$
\begin{aligned}
& \text { APPENDIX } \\
& e_{1}=e^{\frac{\pi}{2 p}-0.5 \beta}+\frac{\pi m}{2 p}-e^{\frac{\theta+0.5 \beta}{a}-m \theta}, \quad e_{2}=e^{m 0.5 \beta}-e^{-m \theta} \text {, } \\
& e_{3}=e^{-0.5 \beta m}-e^{-m \theta+\frac{-\theta+0.5 \beta}{a}}
\end{aligned}
$$

The magnetic flux density variation and magnetic field strength of low carbon steel:

$$
\begin{aligned}
& B_{\mathrm{s}}(\mathrm{T})=-0.003067 e^{0.0091 \mathrm{~T}}+1.63 e^{0.0001313 \mathrm{~T}} \\
& H(B(\mathrm{~T}))=182.1 e^{1.534 B(\mathrm{~T})}+0.07098 e^{6.409 B(\mathrm{~T})}
\end{aligned}
$$

Conductivity of low carbon steel:

$$
\sigma(T)=(1+0.003(T-20))^{-1} 10^{7}
$$

Resistivity of copper: $\rho_{\mathrm{Cu}}(T)=16.8(1+0.00393(T-20)) 10^{-9}$

Specific heat capacity of steel, shaft and copper:

$c_{\text {shaft }}(T)=450+0.28 T-2.91 T^{2} 10^{-4}+1.34 T^{3} 10^{-7}$

$c_{\text {steel }}(T)=425+0.773 T-1.69 T^{2} 10^{-3}+2.22 T^{3} 10^{-6}$

$\mathcal{c}_{\mathrm{Cu}}(T)=383+0.158 T-0.2 T^{2} 10^{-3}+0.2 T^{3} 10^{-6}$

Thermal conductivity of steel, shaft and copper:

$$
\lambda_{\text {steel }}(T)=54-0.0333 T, \lambda_{\text {shaft }}(T)=14.6-0.0127 T \text {, }
$$$$
\lambda_{\mathrm{Cu}}(T)=400.56-0.06831
$$

Mass density of low carbon steel:

$$
\rho_{\mathrm{d}}(T)=8050 /\left(1+10.8 \Delta T 10^{-6}\right) \text { in Kelvin. }
$$

\section{REFERENCES}

[1] J. Tian, D. Li and L. Ye, "Study on Braking Characteristios of a Novel Fddy Current-hydraulic Hybrid Retarder for Heavy-duty Vehicles," in IEEE Trans. on Energy Convers., DOI: 10.1109/TEC.2020.2978304, Early Access.

[2] D. Valderas, I. Mesa, I. Adín, H. Lehmann, G. Lancaster, O. Stark, W. Baldauf, J. d. Portillo, "Modeling eddy current brake emissions for electromagnetic compatibility with signaling devices in high-speed railways," IEEE Trans. on Vehic. Techn., vol. 66, no. 11, pp. 9743-9752, Nov. 2017.

[3] R. Yazdanpanah, M. Mirsalim, "Iybrid electromagnetic brakes: Design and performance evaluation," IEEE Trans. on Energy Con., vol. 30, no. 1 , pp. 60-69, 2015.

[4] L. Ye, Y. Liu, D. Li, "Performance analysis and optimization of liquidcooled and flywheel-type eddy current retarder, IEEE Trans. on Magn., DOI: 10.1109/TMAG.2019.2894771, 2019

[5] H. Shin, J. Choi, H. Cho, S. Jang, "Analytical torque calculations and experimental testing of permanent magnet axial eddy current brake", IEEE Trans. on Magn., vol. 49, no. 7, pp. 4152-4155, 2013.

[6] L. Ye, M. Cao, Y. Liu, D. Li, "Multi-field coupling analysis and demagnetization experiment of permanent magnet retarder for heavy vehicles," IEEE Access, vol. 7, pp. 50734-50745, May 2018.
[7] Y. Jin, L. Li, B. Kou, D. Pan, "Thermal Analysis of a Hybrid Excitation Linear Eddy Current Brake," IEEE Trans. on Ind. Electron., vol. 66, no. 4, pp. 2987-2997, Apr. 2019.

[8] B. Kou, Y. Jin, H. Thang, L. Zhang, H. Zhang, "Analysis and design of hybrid excitation linear eddy current brake", IEEE Trans. on Energy Conv., vol. 39, no. 2, pp. 496-506, 2014.

[9] K. Shin, H. Park, H. Cho, J. Choi, "Semi-Three-Dimensional Analytical Torque Calculation and Experimental Testing of an Eddy Current Brake With Permanent Magnets," IEEE Trans on Appl. Super., vol. 28, no. 3, 2018.

[10] T. Lubin, A. Rezzoug, "3-D Analytical Model for Axial-Flux EddyCurrent Couplings and Brakes Under Steady-State Conditions," IEEE Trans. on Magn., vol. 51, no. 10, ASC: 8203712, 2015.

[11] Y. Lezhi, L. Desheng, M. Yuanjing, J. Jiao, "Design and performance of a water-cooled permanent magnet retarder for heavy vehicles," IEEE Trans. on Energy Conversion, vol. 26, no. 3, pp. 953-958, 2011.

[12] P. Yang, G. Zhou, 7. 7.hu, C. Tang, 7. He and P. Wang, "Tinear Permanent Magnet Eddy Current Brake for Ovenvinding Protection," in IEEE Access, vol. 7, pp. 33922-33931, 2019.

[13] B. Kou, Y. Jin, H. Zhang, L. Zhang, H. Zhang, "Nonlinear Analytical Modeling of Hybrid-Excitation Double-Sided Linear Eddy-Current Brake."IEEE Trans. on Magn., vol. 51, no. 11, ASC: 8003404, 2015.

[14] M. Gulec, E. Yolacan, M. Aydin, "Design, analysis and real time dynamic torque control of single-rotor-single-stator axial flux eddy current brake," IET Elect. Power Appl., vol. 10, no. 9, pp. 869-876, 2016.

[15] A. Hemeida et al., "A Simple and Efficient Quasi-3D Magnetic Fquivalent Circuit for Surface Axial Flux Permanent Magnet Synchronous Machines," in IEEE Transactions on Indtustrial Electronics, vol. 66 , no. 11 , pp. $8318-8333$, Nov. 2019.

[16] B. Guo, Y. Huang, F. Peng, J. Dong and Y. Li, "Analytical Modeling of Misalignment in Axial Flux Permanent Magnet Machine," in IEFE. Transactions on Industrial Electronics, vol. 67, no. 6, pp. 4433-4443, June 2020.

[17] A. Boehm and I. Hahn, "Measurement of magnetic properties of steel at high temperatures," in Proc. IECON Annu. Conf., 2014, pp. 715-721.

[18] J. E. Miller and R. Rabinovici, "Back-EMF waveforms and core lossesin brushless DC motors," IEE Proc. Electr. Power Appl., vol. 141, no. 3, pp. 144-154. May 1994.

[19] C. Chen, Y. Liu and Y. Wang, "A Novel Model of Magnetic Eddy-current Coupling Based on the Magnetio Equivalent Cirouit Method, "in Proc. International Conference on Materials Science and Mechanical Engineering, pp. 104-109, 2016.

[20] W. Guo, D. Li, L. Ye, "A Model of Magnetic Field and Braking Torque in Liquid-Cooled Permanent-Magnet Retarder Accounting for the Skin Effect on Permeability, "IEEE Trans. on Vehic. Techn., vol. 68, no. 11, pp. 10618-10626, Sept. 2019

[21] P. D. Agarwal, "Eddy-current losses in solid and laminated iron," AIEE Trans., vol. 78, part 1, pp. 169-181, May 1959.

[22] J. Pyrhönen, J. Nerg, P. Kurronen and U. Lauber, "High-Speed HighOutput solid-rotor induction-motor technology for gas compression," IEEE Trans. on Ind. Electrn., vol. 57, pp. 272-280, 2010.

[23] J. Nerg, M. Rilla, J. Pyrhönen, "Thermal analysis of radial-flux electrical machines with a high power density," IEEE Trans. on Ind. Electron., vol. 55 , no. 10 , pp. 3543-3354, Oct. 2008.

[24] N. Rostami, M. R. Fevzi, J. Pyrhönen, A. Parviainen, M. Niemelä, “ Lumped-parameter thermal model for axial flux permanent magnet machines," IEEE Trans. on Magn., vol. 49, no. 3, pp. 1178-1184, Mar. 2013. 